\title{
Parental Health Risk Perceptions and Preventive Measures on Children's Exposure to Secondhand Smoke (SHS) of Tobacco Cigarette in Malaysia: A Nationwide Study
}

\author{
Suria JUNUS \\ hospital raja permaisuri bainun \\ Chii-Chii CHEW ( $\nabla$ chiichii.crcperak@gmail.com ) \\ hospital raja permaisuri bainun \\ Pravin SUGUNAN \\ hospital raja permaisuri bainun \\ Nurul-Fazlin MEOR-AZIZ \\ Institute of Training Ministry of Health \\ Nurul Ain ZAINAL \\ Institute of Training Ministry of Health \\ Husna Mat HASSAN \\ Institute of Training Ministry of Health \\ Mazetty-Aiza ABU-MANSOR \\ Institute of Training Ministry of Health \\ Hazirah ABU-ZAMRI \\ Institute of Training Ministry of Health \\ Amar-Singh HSS \\ hospital raja permaisuri bainun
}

Research Article

Keywords: Secondhand smokings, child, parents, awareness, perception, preventive measures

Posted Date: February 15th, 2021

DOI: https://doi.org/10.21203/rs.3.rs-166871/v1

License: (9) This work is licensed under a Creative Commons Attribution 4.0 International License. Read Full License 


\section{Abstract}

Background: Secondhand smoke (SHS) exposure can affect physical development in children. An understanding of parental risk perception of SHS aid in developing protectives measures to prevent children from SHS exposure. This study aimed to assess parental risk perceptions of SHS and action taken by parents in minimising their children from exposing to SHS.

Methods: This cross-sectional nationwide study conducted in 2018 conveniently recruited 289 parents with children up to age 12 at the public areas. Parents were asked to rate the risk level from 1 (no risk) to 5 (extremely high risk) by looking at the photographs of an adult smoked in the presence of a child in 8 different situations. The implementation of smoking restriction rules was assessed. Mean score was calculated with higher scores represent higher risk of SHS to child's health. Linear regression analysis was used to determine factors associated with the level of parental risk perception of SHS exposure to the children's health.

Results: A total of 246 parents responded. Their mean age was 35 years old (SD 6.4), majority were mothers (75.6\%), Malays (72.0\%), had tertiary education level (82.5\%), and had a youngest child with mean age of 3 years (SD 3.1). The risk perception level was high [mean scores: 4.11 (SD: 0.82)]. Most parents implemented household (65.0\%) and car (68.3\%) smoking restriction rules. Negative risk perception level was observed among participants who were fathers with lower occupation class $(p=0.005)$, lived with a smoker $(p=0.023)$, allowed household smoking with open window $(p=0.001)$, being a father and lived with a smoker $(p=0.020)$, and mothers with managerial position while the fathers had a lower occupation class $(p=0.038)$.

Conclusion: Most parents perceived that risks of SHS exposure to their children was high but only two-thirds of them had set smoking prohibiting rules. Health policymaker should pay attention to tactors associated with negative risk perceptions among parents.

Trial registration: This study is approved by Medical Research Ethics Committee, Ministry of Health Malaysia (Registration Number: NMRR-18-3299-44967).

\section{What Is Already Known On This Topic?}

1. Exposure of children to secondhand smoke is of no risk-free level.

2. Secondhand smoke harms children and adults, and the only way to fully protect non-smokers is to eliminate smoking in homes, worksites, and public places.

3. Separating smokers from non-smokers, opening windows, or using air filters does not prevent people from breathing secondhand smoke.

\section{What Findings Study Adds?}

1. Majority of parents perceived that the risk of children exposure to secondhand smokes (SHS) was high. Most parents perceived that the cigarette smoke will harm the children if someone is smoking in the closed area such as kitchen.

2. Of concern, almost one-third of the participants did not set smoking rule restrictions inside the house or in the car. Nevertheless, most of them had taught their children to stay away from smokers

3. Father with lower working class, parents who allowed house smoking with open window, being a father and the presence of family member who was a smoker were factors significantly associated with negative risk perception of secondhand smoke exposure to children. Policy maker should consider raising awareness by focusing on the group of parents with these factors to attain maximal effect.

\section{Introduction}

Secondhand smoke (SHS) is defined as a person involuntarily expose to tobacco smoke generated by a smoker or by burning of tobacco products. SHS is proved harmful to health as the smoke contains 70 types of carcinogens(1) and had caused 2,500,000 non-smokers have died from adverse health outcomes $(2,3)$. The economic burden attributed to cost in treating SHS-related illness and death in children and adults is summed up to USD \$267 million annually (4). Children are particularly vulnerable to harm of SHS because of their growing bodies and faster breathing rate than adults. Approximately $40 \%$ of children are exposed to SHS 
worldwide (5). The harmful effect in children has been characterised by increased risk for respiratory symptoms and infections, and reduced rate of lung growth (6).

While no amount of SHS is risk-free for children (1) having an understanding on the parental risk perception dimension of SHS exposure in children is one of the important constitutes in developing effective intervention to protect children from SHS $(7,8)$. Socio-demographic characteristic including parental smoking behaviour, ethnicity and children' age were found associated with parental risk perception of SHS exposure to children $(7,9)$. Parents who with higher risk perception of SHS exposure to children's health are those who being more protective and practicing smoked away from home. Russian parents showing lower risk perceptions less than parents of other origins (9). In Malaysia, adolescent who were Malays and descendants of natives of Sabah and Sarawak were more likely to expose to SHS than those with the Chinese and Indian parents (10). Parental smokers with children younger than 3 years of age practicing stricter ban of smoking than parents with children of older age groups (8). Parents were 3.5 times more likely in using tobacco products in the vicinity of the house when there was a smoker in the family (11). Determining factors affecting the risk perception of SHS exposure among parents are important for strategy planning as study recommended that interventions targeting parents with specific characteristics that affect the practice of SHS exposure to children are more effective than having interventions for all smoker parents $(7,8)$.

Smoking bans and restrictions legislation are proven to be the most effective method for reducing SHS exposure (6), and this measure can be applied in the public area. Nevertheless, these rules are deemed hard to be enforced at home setting and inside a private car. In the United States, household smoking restrictions reported by adults had been increased from $69.3 \%$ to $79.5 \%$ and car smoking prohibitions increased from $68.3 \%$ to $81.8 \%$ in the period of 15 years since year 2000 (12). A relatively lower rate of household smoking restriction reported by Malaysian adolescents who lived with smoking parents (67\%) in which less than twothird (60.8\%) of the household applied this rule at home (13). In general, less than half (40.9\%) of the Malaysian population adopted household smoking restriction (14). The parental perspectives in regards to this practice is yet to be explored. The Malaysian adolescent reported that SHS exposure inside the car of their parents/guardians in the past one week was at the prevalence of $23.3 \%$ (10). It is uncertain if car smoking prohibition has been practiced by the Malaysian parents.

Evidence showed that there was no intervention effect to reduce SHS in children by introducing parental smoking cessation (15). it is vital for parents to set rules that disallow anyone including themselves to smoke at these area (16). Gauging the perspectives among parents of young children in practicing such rules at these settings will provide an idea about the level of parental awareness regarding this issue. In view of great variations in socio-demography features, smoking behaviour and multi-ethnic groups in this country - Malaysia, this study aimed to determine the health risk perceptions of parents with regards to children exposed to SHS and their practice in protecting the children from SHS.

\section{Methodology Study design \& setting}

This cross-sectional nationwide study, conducted from October 2018 till April 2019, involved the collection of data from 13 states and 2 federal territories in Malaysia. Eligible participants were recruited at the public areas including shopping malls, playgrounds, and food courts.

\section{Population \& sample size}

The study included parents who have at least one child aged 12 years and less. The sample size was calculated based on the prevalence of smoking among Malaysian adults in which the highest percentage of $25 \%$ was reported by the National health and Morbidity Survey-Report in 2015 (Institute for Public Health, 2015). Minimum sample size of 289 parents' was required to detect the prevalence of $25 \%$ adult smoking by setting the precision level at $5 \%$ and confidence level of $95 \%$. A total of 360 participants was estimated after considering $20 \%$ of non-response rate. 24 participants were needed to sample from each state and federal territory.

\section{Instrument}


A validated questionnaire measuring parental risk perception of SHS on their children's health was adapted from Myers, et al, 2018 (18). The instrument had a good reliability coefficient of Cronbach's alpha of 0.934 and valid construct to quantify the parents' perceptions of children's exposure to tobacco smoke. In the consideration of study feasibility in collecting nationwide data, only the third section i.e. items with eight photographs was extracted. This adaptation did not violate the validity of the questionnaire after confirming with the author. The photographs showed parents smoking in the presence of young children at various setting (indoor open window, closed room, outdoor) at different distances. Respondents were required to rate the risk level of SHS exposure on young children's health based on a 5-point Likert scale ranging from 0 (no risk) to 4 points (extremely high risk). Meanwhile, questionnaire from Ratajczak A, et al, 2018 was adapted to assess if parents had implemented household and car smoking restriction rules as preventive measures to protect their children from exposing to SHS (19). An addition question was added as a separate section to explore if parents had taught their children to stay away from smoker as a measure to avoid from SHS (16).

The questionnaire was translated into Malay language via forward and backward translation. Questionnaires in English and Malay underwent content and face validation among 2 paediatricians, and pre-tested among 10 parents for each language. Then, both English and Malay questionnaire were built into online electronic form (Google Forms).

\section{Data collection}

Data collectors identified from each state identified were sent an instructional document specifying the procedures of data collection. If both parents were presence during the recruitment, both were invited to participate in this study, and they were required to answer the questionnaire separately. This allowed each parent to give response without being influenced by the others. Parents who agreed to participate were required to give online informed consent and answering the questionnaire on the mobile device provided by the data collector to ensure only one entry from each participant.

\section{Data Analysis and Interpretation}

All statistical tests were analysed using SPSS version 20 (IBM Corp. Released 2011. IBM SPSS Statistics for Windows, Version 20.0. Armonk, NY: IBM Corp). Parental occupation was coded based on Standard Occupational Classification 2010 (20).

Descriptive analysis was used to summarise participants' characteristics. Mean score was calculated by summing up the score given for each item where higher scores represent higher risk of SHS to child's health (18). Linear regression analysis was used to determine factors associated with the level of parental risk perception of SHS exposure to the children's health. Assumptions were checked, no multicollinearity problem was detected and $p$-value less than 0.05 was considered statistically significant.

\section{Results}

A total of 246 parents participated (response rate was $85.1 \%$ ). The mean age of parents was 35 years old (SD 6.4), most of the participants were mother (75.6\%), Malay ethnicity (72.0\%), had received tertiary education (82.5\%). More than half of the participants' occupation was classified as intermediate level [mother $(64.2 \%)$ and father $(52.8 \%)$ ]. Intermediate occupation is defined as works that do not involve general planning or supervisory.(20) Majority of parents (87.0\%) were non-smokers. Approximately one-third (33.7\%) of the participant's declared that they had a tobacco cigarettes smoker living with them in the same house. Most parents had more than one child at home (76.0\%) with a maximum of 12 children were reported by one parent, the mean age of the youngest child was 3 years (SD 3.1) (Table 1).

Table 1: Characteristics of the participants 


\begin{tabular}{|c|c|c|}
\hline Variables & & $\mathrm{n}=249, \mathrm{n}(\%)$ \\
\hline Parent's age, mean (SD) & & $35(6.4)$ \\
\hline \multirow[t]{2}{*}{ Parental role } & Mother & $186(75.6)$ \\
\hline & Father & $60(24.4)$ \\
\hline \multirow[t]{6}{*}{ Ethnicity } & Malay & $177(72.0)$ \\
\hline & Bumiputera Sabah & $22(8.9)$ \\
\hline & Chinese & $20(8.1)$ \\
\hline & Indian & $16(6.5)$ \\
\hline & Bumiputera Sarawak & $7(2.8)$ \\
\hline & Others & $4(1.6)$ \\
\hline \multirow[t]{2}{*}{ Education Level } & Secondary & $43(17.5)$ \\
\hline & Tertiary & $203(82.5)$ \\
\hline \multirow[t]{6}{*}{ Mother's Occupation ${ }^{a}$} & Managerial and professional & $9(3.7)$ \\
\hline & Intermediate* & $158(64.2)$ \\
\hline & Small employer/ own company & $7(2.8)$ \\
\hline & technical & $9(3.7)$ \\
\hline & Semi-routine/ routine & $14(5.7)$ \\
\hline & Never worked/ unemployed & $49(19.9)$ \\
\hline \multirow[t]{6}{*}{ Father's Occupation ${ }^{a}$} & Managerial and professional & $9(3.7)$ \\
\hline & Intermediate* & $130(52.8)$ \\
\hline & Small employer/ own company & $25(10.2)$ \\
\hline & technical & $40(16.3)$ \\
\hline & Semi-routine/ routine & $32(13.0)$ \\
\hline & Never worked/ fulltime unemployed & $10(4.1)$ \\
\hline \multirow[t]{3}{*}{ Parent's smoking status } & Current smoker & $17(6.8)$ \\
\hline & Former smoker & $15(6.1)$ \\
\hline & Never smoke & $217(87.1)$ \\
\hline Living with extended family member who was a smoker & & $83(33.7)$ \\
\hline \multirow[t]{8}{*}{ Number of children at home } & 1 & $59(24.0)$ \\
\hline & 2 & $89(36.2)$ \\
\hline & 3 & $46(18.7)$ \\
\hline & 4 & $29(11.8)$ \\
\hline & 5 & $17(6.9)$ \\
\hline & 6 & $4(1.6)$ \\
\hline & 9 & $1(0.4)$ \\
\hline & 12 & $1(0.4)$ \\
\hline
\end{tabular}


a The National Statistics Socio-economic Classification rebased on Standard Occupational Classification 2010 (SOC 2010)

*Intermediate occupations include clerical, sales, services, and technical occupation that do not involved general planning or supervisory power (SOC 2010).

\section{Parental risk perception of secondhand smokes (SHS) on children health}

Overall, the mean scores of parental risk perception was 4.11 (SD: 0.82), considerably high risk of SHS exposure to child's health. Majority of the participants (ranging from $35.4 \%$ to $59.3 \%$ ) rated most of the situations of SHS exposure as extremely high risk to the child's health. 'Extremely high risk' was the most frequently rated by the participants for a situation where an adult smoked in the presence of a child in the kitchen (59.3\%) (Photograph 3), followed by adult smoked inside the car with window open while the child was sitting at the rear seat (54.1\%).

Almost equal proportion of the participants rated high risk (33.7\%) and extremely high risk (35.4\%), respectively, for the situation demonstrating an adult smoked at the balcony with opened door while children was playing inside the house (Photograph 7).

Nevertheless, two situations where most parents perceived a relatively lower risk to child's health including an adult smoked in the presence of a child at the playground (42.3\%) (Photograph 2), and an adult smoked at some distance away from a child at the outdoor area (34.1\%) (Photograph 4). The category of 'no risk' was rated the most by the participants for photograph 4 (8.1\%) compared to other situations (ranged from $0.8 \%$ to $2.8 \%$ ) (Table 2 ).

Table 2: Parental risk perception on SHS to children's health 


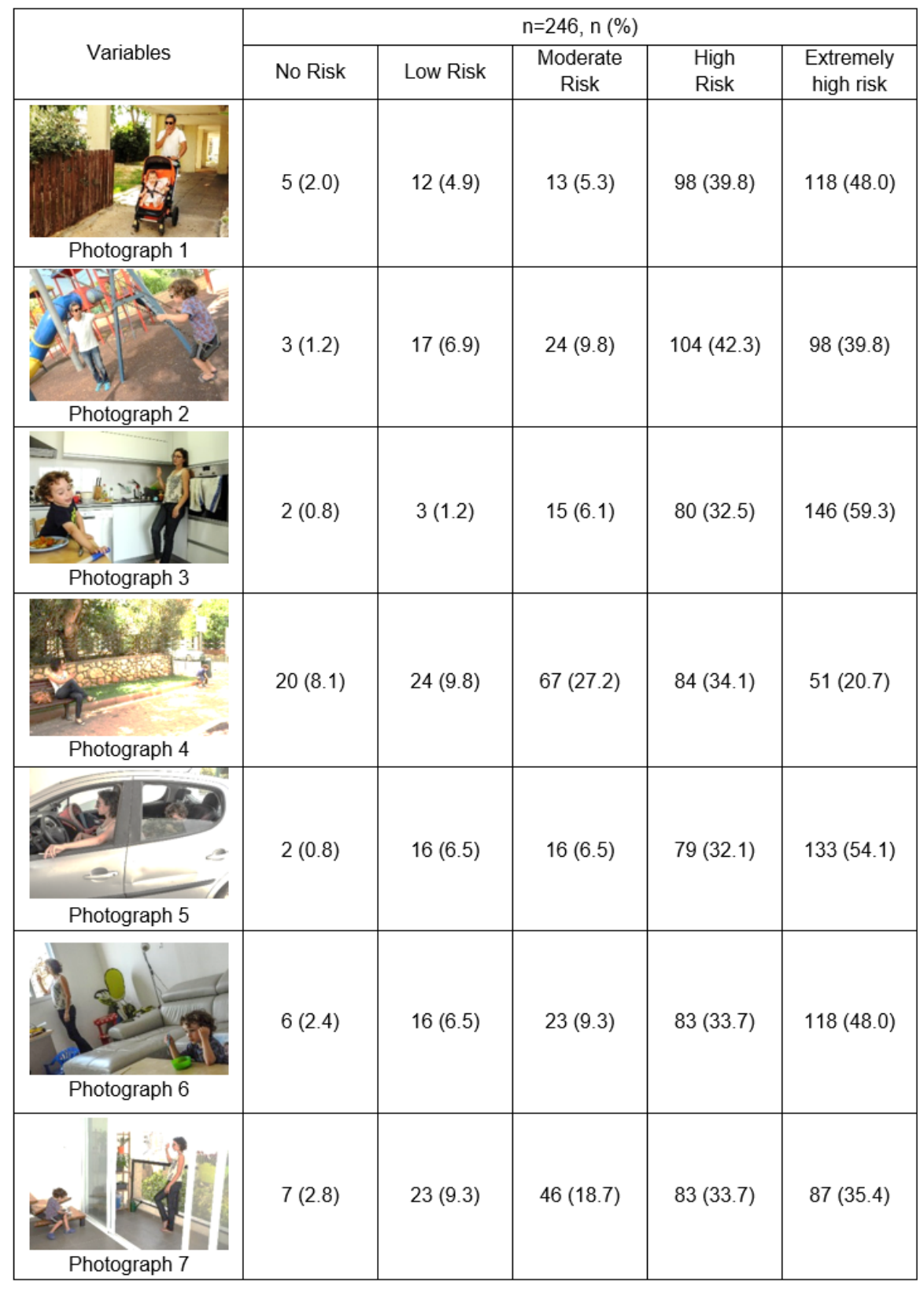

\section{Action taken to protect children from SHS}

About two-third of the parents $(65.0 \%)$ had implemented the home smoking rule by prohibiting smoking inside the house and only $3.3 \%$ of parent's made exception for smokers to smoke with window open. About $68.3 \%$ of parents forbid smoking inside the car when travelling with children. Nevertheless, $6.9 \%$ of parents allowed smoking inside the car with window opened. Majority of the parents $(85.4 \%)$ had taught their children to stay away from cigarette smokers.

\section{Factors associated with parental risk perception of SHS to the child's health}

Mothers worked in the professional position $(\beta=0.63, p=0.008)$ and had a semi-routine or routine work $(\beta=0.47, p=0.014)$, and participants who have taught their children to stay away from smoker had significant positive in risk perception $(\beta=0.42, p<0.001)$.

Fathers who worked as small employer or owned a company $(\beta=-0.57, p=0.005)$, participant who lived with smokers $(\beta=-0.22$, $p=0.023)$, allowed household smoking with open window $(\beta=-0.82, p=0.001)$ were associated with negative risk perception. Risk perception was decreased by 0.58 unit when the parental role was father and lived with an extended family who was a smoker 
$(p=0.020)$. The condition of mother with professional position while father worked as small employer or own a company was found associated with reduction in risk perception by 1.45 unit $(p=0.038)$ (Table 3$)$.

Table 3: Factors associated with parental risk perception of SHS to child's health

\begin{tabular}{|c|c|c|c|c|}
\hline Variables & $\begin{array}{l}\text { Adj. } \\
b^{\S}\end{array}$ & $95 \% \mathrm{Cl}$ & $\begin{array}{l}\text { t- } \\
\text { statistics }\end{array}$ & $\begin{array}{l}p- \\
\text { value }\end{array}$ \\
\hline \multicolumn{5}{|l|}{ Parental role } \\
\hline Father & -0.21 & $\begin{array}{l}-0.44 \\
0.02\end{array}$ & -1.826 & 0.069 \\
\hline \multicolumn{5}{|l|}{ Mother's Occupation ${ }^{a}$} \\
\hline Managerial \& professional & 0.63 & $\begin{array}{l}0.16 \\
1.10\end{array}$ & 2.665 & 0.008 \\
\hline Intermediate & 0.20 & $\begin{array}{l}0.00 \\
0.40\end{array}$ & 1.927 & 0.055 \\
\hline Semi-routine/ routine & 0.47 & $\begin{array}{l}0.10 \\
0.84\end{array}$ & 2.488 & 0.014 \\
\hline Have taught child to stay away from smoker & 0.42 & $\begin{array}{l}0.18 \\
0.65\end{array}$ & 3.531 & $<0.001$ \\
\hline \multicolumn{5}{|l|}{ Father's Occupation ${ }^{a}$} \\
\hline Small employer/ own company & -0.57 & $\begin{array}{l}-0.97 \\
-0.17\end{array}$ & -2.808 & 0.005 \\
\hline Lived with an extended family member who was a smoker & -0.22 & $\begin{array}{l}-0.41 \\
-0.03\end{array}$ & -2.292 & 0.023 \\
\hline Allowed household smoking with open window & -0.82 & $\begin{array}{l}-1.28 \\
-0.36\end{array}$ & -3.483 & 0.001 \\
\hline Father* Lived with an extended family member who was a smoker & -0.58 & $\begin{array}{l}-1.07 \\
-0.09\end{array}$ & -2.338 & 0.020 \\
\hline Father*Current smoker & -0.38 & $\begin{array}{l}-0.86 \\
0.10\end{array}$ & -1.576 & 0.116 \\
\hline $\begin{array}{l}\text { Mother with managerial \& professional occupation* father as small employer/ own } \\
\text { company }\end{array}$ & -1.45 & $\begin{array}{l}-2.81 \\
-0.08\end{array}$ & -2.090 & 0.038 \\
\hline Mother's intermediate occupation* father as small employer/ own company & 0.58 & $\begin{array}{l}-0.00 \\
1.17\end{array}$ & 1.962 & 0.051 \\
\hline \multicolumn{5}{|c|}{$\S$ Adjusted regression coefficient analyzed by Multiple linear regression, $F(2,232)=16.296, p<0.001, R^{2}=0.46$. } \\
\hline \multicolumn{5}{|l|}{ Cl: confidence interval, Bold $p$-value: statistically significant } \\
\hline
\end{tabular}

\section{Discussion}

Despite the parents were aware of high risk of SHS exposure to children's health, the implementations of household and car smoking restriction rules remained inadequately practice among parents. Factors associated with negative parental risk perception in SHS exposure to children health were important inputs for public health policymakers in designing strategy to protect the children from SHS.

Parent who being a father and living an extended family member who was a smoker were negatively associated with risk perception of SHS exposure to children' health. These characteristics were similar to studies researching on parents in this country 
and Indonesia. Children living with smoker father and an extended family member who was a smoker were more likely to expose to SHS $(21,22)$. A local study reported in 2011 found that children with such family background were detected with higher level of GM cotinine concentration $(0.71 \mathrm{ng} / \mathrm{mL})$ compared to children living in a non-smoking family $(0.32 \mathrm{ng} / \mathrm{mL})(21)$. Negative parental risk found in this study could be reflecting that the problem of SHS exposure in children had not been improved since then. The efforts in increasing parental awareness remains inadequate and specific attention should be paid to father lived with a family member who smoked.

Negative parental risk perception also seen in parents allowed household smoking with open window. Similar study showed that parents who allowed household smoking and parents themselves smoking inside the house were found associated with lower parental perception exposure of SHS in children than those smoke strictly outside the house (9). Research showed that up to $52 \%$ of the smoker parents reported not believing or not aware about SHS-related adverse health effects in children (23). Lack awareness about 'no risk-free level of SHS exposure to children could be the reason of parents allowed smoking inside the house as seen in this study (1). Study demonstrated that despite preventive measures have been taken by parents living with a smoker to protect their children from SHS, the biomarker of SHS exposure detected in children was 5 to 7 times higher than children lived in smoking-free household. Studies recommended that only a strict household smoking ban can effectively protect children from SHS $(6,24)$. The awareness about this fact should be promoted especially among parents living with smokers.

Negative risk perception were observed in fathers with lower working class. Low socioeconomic status have always been independent factors related to SHS exposure among children at home. Children had significantly lower GM cotinine level whose fathers in the managerial/professional $(0.37 \mathrm{ng} / \mathrm{mL})$, manual non-skilled $(0.45 \mathrm{ng} / \mathrm{mL})$ and skilled worker $(0.44 \mathrm{ng} / \mathrm{mL})$ than those whose fathers in the armed forces groups $(0.77 \mathrm{ng} / \mathrm{mL})$. In addition, the parental risk perception was changed from positive to negative when a family comprised of a mother who worked as professional position while the father had a lower working class occupation. This suggested that parental risk perception could be affected by the paternal working class. It was recommended that socially disadvantage parents should be given practical support including engaged them in quit smoking programme or helping them to change their attitude to smoke only outside the home if the parents were unwilling to quit smoking (25).

Smoking restrictions rules were practice in approximately two-third of the parents. This rate is similar to those reported in a study reported by Malaysian adolescents where $60.8 \%$ of their household implemented these rules back in 2014 (13). Household smoking restriction is suggested as an effective way to minimize the exposure of SHS in children (26). The rate remains similar across the years warrant the attentions of public health policymakers to enhance the awareness among parents in this aspect.

\section{Limitations}

Despite this study having covered every state in Malaysia, the population recruited might not adequately represent the proportion of all ethnic groups in this country as most of the respondent were Malay (72\%). The distribution of ethnicities in Malaysia is comprised of approximately 69\% Bumiputera (Malays, Indigenous people including Orang Asli, Sabah and Sarawak Bumiputera), $23 \%$ Chinese, $6.9 \%$ Indians, and $1.0 \%$ others ethnicity in year 2018. The actual risk perception among parent could be lowered because there was less than $7 \%$ of the parents recruited were smokers and this rate was less than the prevalence of smokers (25\%) reported at national level (9). and smoker parents ranged from 44.3 to 67\% between year 2011 and $2013(13,21)$.

\section{Implications for health policymakers}

It is important for parents to aware about the risk of exposure to SHS to prevent any untoward event for the children growth and wellbeing. The study findings showed lack of clear rules prohibiting someone from smoking directly in front of the children, especially in closed areas or inside the car. Parents give exception for smokers to smoke with open windows in the house or when travelling with children in the car, situations which could expose the children to SHS. Additionally, public health officers should raise awareness among the parents by educating them about the harm of SHS exposure to their children and should consider setting rules that completely prohibit smoking in the house and inside the car regardless of the situation. The groups of parents who should be targeted awareness activities are fathers with lower working class and lived with a family member who smoked. 


\section{Conclusion}

Majority of the parents perceived high risk of SHS exposure among the children and they have taught their children to stay away from cigarette smokers. However, only two-third of them set rules to prohibit smoking inside the house and car. The paternal role, parents' occupations, the presence of a family member who smoked, not completely restricting household smoking were factors significantly associated with negative parental risk perception on the SHS exposure to their children's health. Health policymakers should consider creating a regular program to raise awareness targeting parents with these characteristic by introducing them regarding risk of exposure to SHS among children at different situations and emphasizing the importance of practicing strict smoking restriction rules.

\section{Abbreviations}

SHS: Secondhand smoke

\section{Declarations}

\section{Ethics approval and consent to participate}

The ethics approval was obtained from the Malaysian Medical Research Ethical Committee. The study was also registered with the National Medical Research Registry under the protocol number: NMRR-18-3299-44967. Informed consent from the participants was obtain prior to data collection. This study was conducted in accordance with the Malaysian NIH Guidelines for Conducting Research in the $\mathrm{MOH}$ Institutions \& Facilities.

\section{Consent for publication}

All authors agreed to submit to BMC Public Health for publication.

\section{Availability of data and materials}

The datasets generated during the current study are not publicly available due confidentiality but are available from the corresponding author on reasonable request.

\section{Declaration of Conflicting Interests}

The author(s) declared no potential conflicts of interest with respect to the research, authorship, and/or publication of this article.

\section{Funding}

The author(s) received no financial support for the research, authorship, and/or publication of this article.

\section{Authors' contributions}

The SJ and CCC analysed, interpreted and wrote the first draft of this study, PS reviewed and proof read this article. NFMA, NAZ, HAH, MAAM, HAZ collected and entered the data. ASH supervised this study throughout and contributed idea to this study. All author read, reviewed and approved this manuscript.

\section{Acknowledgments}

We would like to express our sincere gratitude to parents responded to this study and thanks to everyone who had helped and guided our group in this study. Thanks owe to Vicki Myers for sharing and allow us to use her validated tool to conduct this research. Some of the findings of this study had been shared in poster presentation in 13th MOH-AMM Scientific Meeting 2019. We would like to thank the Director General of Health Malaysia for his permission to publish this article.

\section{Disclosure}


The views, interpretations, implications, conclusions and recommendations expressed in this paper are those of the authors alone and do not necessarily represent the opinions, views and policy of the Ministry of Health Malaysia. Authors declare no conflict of interest and this study was self-funded.

\section{References}

1. Centres of Disease Control and Prevention. Health Effects of Secondhand Smoke [Internet]. 2020 [cited 2020 Nov 12]. Available from:

https://www.cdc.gov/tobacco/data_statistics/fact_sheets/secondhand_smoke/health_effects/index.htm\#: :text=Secondhand smoke causes lung cancer in adults who have never smoked.\&text=4-,Nonsmokers who are exposed to secondhand smoke at home or,cancer by $20-3$

2. United States Department of Health and Human Services. The Health Consequences of Smoking -50 Years of Progress $A$ Report of the Surgeon General. A Rep Surg Gen. 2014;1081.

3. Öberg M, MS J, A P-Ü, C S, A W. Second-hand smoke: assessing the burden of disease at national and local levels [Internet]. Vol. WHO Enviro, World Health Organization. Geneva:; 2010. Available from: https://www.who.int/quantifying_ehimpacts/publications/SHS.pdf

4. Mason J, Wheeler W, Brown MJ. The economic burden of exposure to secondhand smoke for child and adult never smokers residing in U.S. public housing. Public Health Rep. 2015;130(3):230-44.

5. Oberg M, Jaakkola MS, Woodward A, Peruga A, Prüss-Ustün A. Worldwide burden of disease from exposure to second-hand smoke: a retrospective analysis of data from 192 countries. Lancet (London, England). 2011 Jan;377(9760):139-46.

6. U.S. Dept. of Health and Human Services, Centers for Disease Control and Prevention, Coordinating Center for Health Promotion, National Center for Chronic Disease Prevention and Health Promotion O on S and H. The Health Consequences of Involuntary Exposure to Tobacco Smoke: A Report of the Surgeon General. Vol. 199, Centers for Disease Control and Prevention. 2006. p. 611-3.

7. Rosen L, Kostjukovsky I. Parental risk perceptions of child exposure to tobacco smoke. BMC Public Health. 2015;15(1).

8. Mahabee-Gittens EM, Merianos AL, Stone L, Tabangin ME, Khoury JC, Gordon JS. Tobacco Use Behaviors and Perceptions of Parental Smokers in the Emergency Department Setting. Tob Use Insights. 2019;12:1179173X1984139.

9. Myers V, Rosen LJ, Zucker DM, Shiloh S. Parental perceptions of children's exposure to tobacco smoke and parental smoking behaviour. Int J Environ Res Public Health. 2020;17(10).

10. Lim KH, Lim HL, Ghazali SM, Kee CC, Teh CH, Gill BS, et al. Malaysian adolescents' exposure to secondhand smoke in the car of their parents/guardians: A nationwide cross-sectional school-based study. Tob Induc Dis. 2020;18:1-8.

11. Ríos S, Concha J, Mauricio Barría R. Measures stated by parents and caregivers of infants, toddlers, and preschoolers to prevent environmental tobacco smoke exposure. Arch Argent Pediatr. 2018;116(4):262-8.

12. McMillen R, Wilson K, Tanski S, Klein JD, Winickoff JP. Adult attitudes and practices regarding smoking restrictions and child tobacco smoke exposure: 2000 to 2015. Pediatrics. 2018;141(January 2018):S21-9.

13. Abidin NZ, Zulkifli A, Abidin EZ, Rahman AA, Hashim Z, Rasdi I, et al. Secondhand smoke exposure in toddlerhood and cognitive ability among Malaysian adolescents. Iran J Public Health. 2014;43(January 2014):131-41.

14. Hock LK, Li LH, Cheong KC, Ghazali SM, Pei HP, Kang CY, et al. Prevalence and factors associated with total smoking restriction at home in Malaysia: Findings from a nationwide population-based study. Malaysian J Med Heal Sci. 2019;15(3):20-8.

15. Daly JB, Mackenzie LJ, Freund M, Wolfenden L, Roseby R, Wiggers JH. Interventions by Health care professionals who provide routine child health care to reduce tobacco smoke exposure in children a review and meta-Analysis. JAMA Pediatr. 2016;170(2):138-47.

16. Center for Disease Control. How We Can Protect Our Children from Secondhand Smoke: A Parent's Guide | CDC [Internet]. 2019. Available from: https://www.cdc.gov/tobacco/basic_information/secondhand_smoke/protect_children/generalpopulation/index.html

17. Institute for Public Health (IPH). National Health and Morbidity Survey 2015 (NHMS 2015) Vol. II: Non-Communicable Diseases, Risk Factors \& Other Health Problems. 2015.

Page $11 / 12$ 
18. Myers V, Shiloh S, Rosen L. Parental perceptions of children's exposure to tobacco smoke: Development and validation of a new measure. BMC Public Health. 2018;18(1):1-11.

19. Ratajczak A, Ratajczak K, Feleszko W. A cross-sectional study of smoking behaviors and attitudes of parents in pediatric primary care settings. Int J Environ Res Public Health. 2018;15(7).

20. ONS. Standard Occupational Classification 2010 - Volume 1: Structure and descriptions of unit groups. Vol. 1, Office for National Statistics. 2010. 284 p.

21. Abidin E, Semple S, Omar A, Rahman HA, Turner SW, Ayres JG. A survey of schoolchildren's exposure to secondhand smoke in Malaysia. BMC Public Health [Internet]. 2011;11(1):634. Available from: http://www.biomedcentral.com/1471-2458/11/634

22. Nadhiroh SR, Djokosujono K, Utari DM. Socioeconomic characteristics, paternal smoking and secondhand tobacco smoke exposure among infants in Jakarta, Indonesia. Tob Induc Dis. 2020;18(May):1-9.

23. Ribeiro FADC, De Moraes MKR, De Morais Caixeta JC, Da Silva JN, Lima AS, Parreira SLS, et al. Perception of parents about second hand smoke on the health of their children: An ethnographic study. Rev Paul Pediatr [Internet]. 2015;33(4):394-9. Available from: http://dx.doi.org/10.1016/j.rppede.2015.08.010

24. Blackburn C, Spencer N, Bonas S, Coe C, Dolan A, Moy R. Effect of strategies to reduce exposure of infants to environmental tobacco smoke in the home: Cross sectional survey. Br Med J. 2003;327(7409):257-60.

25. Orton S, Jones LL, Cooper S, Lewis S, Coleman T. Predictors of children's secondhand smoke exposure at home: A systematic review and narrative synthesis of the evidence. PLoS One. 2014;9(11).

26. Park MB. Living with parents who smoke predicts levels of toxicant exposure in children. Sci Rep [Internet]. 2020;10(1):1-9. Available from: http://dx.doi.org/10.1038/s41598-020-66920-y 